\title{
Preparation of Nitrogen-Doped Porous Carbon from Melamine- Formaldehyde Resins Crosslinked by Phytic Acid
}

\author{
Wei Xiong ${ }^{1,2}$, Ji Hoon Kang ${ }^{1}$, and Yongju Jung ${ }^{1, *}$ \\ ${ }^{1}$ Department of Chemical Engineering, Korea University of Technology and Education \\ (KOREATECH), Cheonan 31253, Republic of Korea \\ ${ }^{2}$ School of Chemistry and Environmental Engineering, Wuhan Institute of Technology, 693 Xiongchu \\ Road, Wuhan 430073, P. R. China \\ *E-mail: yjung@koreatech.ac.kr
}

doi: $10.20964 / 2018.01 .45$

Received: 17 September 2017 / Accepted: 11 November 2017 / Published: 16 December 2017

\begin{abstract}
A new approach for the fabrication of nitrogen-doped hierarchical porous carbon (NHPC) is presented on the basis of the carbonization of melamine-formaldehyde resins crosslinked by phytic acid. The specific surface area and micropore volume of NHPC greatly increased with an increase in carbonization temperature. The NHPC sample (NHPC-850) synthesized at $850{ }^{\circ} \mathrm{C}$ showed a high surface area $\left(2732 \mathrm{~m}^{2} / \mathrm{g}\right)$ and a large pore volume $\left(1.46 \mathrm{~cm}^{3} / \mathrm{g}\right)$ with hierarchical porous structures of macro-, meso- and micropores. It is thought that phytic acid contributed to increasing the space between carbon frameworks during carbonization. This increase allowed $\mathrm{KOH}$ to be more uniformly distributed in the carbon framework, leading to a more effective activation process. NHPC-850 exhibited excellent electrochemical performance in an aqueous 6.0 $\mathrm{M} \mathrm{KOH}$ solution, including a high specific capacitance $(271 \mathrm{~F} / \mathrm{g}$ at $1.0 \mathrm{~A} / \mathrm{g})$, an excellent rate property of $70 \%$ at $10.0 \mathrm{~A} / \mathrm{g}$, and $\sim 100 \%$ retention after 500 cycles.
\end{abstract}

Keywords: Nitrogen-doped hierarchical porous carbon, melamine-formaldehyde resin, supercapacitor, phytic acid, crosslinker

\section{FULL TEXT}

(C) 2018 The Authors. Published by ESG (www.electrochemsci.org). This article is an open access article distributed under the terms and conditions of the Creative Commons Attribution license (http://creativecommons.org/licenses/by/4.0/). 